\title{
COMPARAÇÃO DA COMUNIDADE ZOOPLANCTÔNICA DE DOIS CORPOS D'ÁGUA DA SERRA DA MANTIQUEIRA-MG
}

\author{
Karin de Paula Reis ${ }^{1}$
}

Karime de Araujo Paina ${ }^{2}$

Maria José dos Santos Wisniewski ${ }^{3}$

\begin{abstract}
RESUMO
A Serra da Mantiqueira é uma área prioritária de conservação com muitos corpos d'água pequenos, rasos e colonizados por macrófitas. Este estudo teve como objetivo realizar um levantamento da comunidade zooplanctônica em dois corpos d'água de pequena extensão e profundidade, em propriedades rurais da região da Serra da Mantiqueira Camanducaia/ Monte Verde-MG. Foram realizadas coletas qualitativas (rede de $68 \mu \mathrm{m}$ ) e quantitativas (100L) a partir da margem do corpo d'água, nos meses de fevereiro e junho de 2010. As variáveis físicas e químicas ( $\mathrm{pH}$, condutividade elétrica, temperatura e oxigênio dissolvido) da água foram medidas com multisensor Horiba U-22 e foram coletadas amostras de água para determinação de clorofila, nutrientes e material em suspensão. Os resultados das variáveis físicas e químicas evidenciaram uma variação sazonal com aumento nas temperaturas da água e condutividade elétrica. A comunidade zooplanctônica foi representada por 26 espécies distribuídas entre Cladocera, Copepoda e Rotifera, com grande riqueza de espécies de Rotifera devido sua ampla distribuição, seguido por Cladocera, em que a família Chydoridae (6) foi a mais representativa devido à presença de macrófitas nos corpos d'água. Os dois corpos d'água estão em processo de eutrofização, foram caracterizados como oligotróficos na primeira coleta e na segunda o açude Pinga da Banana foi mesotrófico o que pode ter ocasionado as altas densidades de organismos e a ocorrência de macho de Cladocera.
\end{abstract}

PALAVRAS-CHAVE: Zooplâncton. Áreas prioritárias. Biodiversidade.

\section{TWO ZOOPLANKTON COMMUNITY COMPARISON OF BODIES OF WATER OF MANTIQUEIRA MOUNTAINS -MG}

\footnotetext{
${ }^{1}$ Mestrado Ecologia e Tecnologia Ambiental, Universidade Federal de Alfenas. karinreis@hotmail.com

${ }_{2}^{2}$ Graduação Ciências Biológicas, Universidade Federal de Alfenas. karime_paina@hotmail.com

${ }^{3}$ Doutorado, Universidade Federal de Alfenas. czw@uol.com.br
} 


\begin{abstract}
The Serra da Mantiqueira is a priority area of conservation with many small and shallow water bodies that are colonized by macrophytes. The purpose of this study is to analyze the numbers of a zooplankton community in two water bodies of small extension and depth found in rural properties located in the region of Serra da MantiqueiraCamanducaia/ Monte Verde - MG. There were two types of evidence collections that were realized, qualitative (net of $68 \mathrm{um}$ ) and quantitative (100l), by the water body shore during the months of February and June of 2010. The physical and chemical variables ( $\mathrm{pH}$, electric conductivity, temperature, and dissolved oxygen) of the water were measured with the multisensor Horiba U-22 and were also collected water samples in order to determine the rate of chlorophyll, nutrients, and suspended materials. The results of the physical and chemical variables demonstrated a seasonal variation with the increasing of the water temperature and electric conductivity. The zooplankton community was represented by 26 species distributed among Cladocera, Copepoda and Rotifera, where there was rich concentration of species of Rotifera because of its wide distribution, followed by Cladocera, in which the Chydoridae family was represented in greatest amount because of the presence of macrophytes in the water bodies. The two water bodies are in the process of eutrophication; they were characterized as oligotrophic in the first collection and in the second collection, the lake Pinga da Banana was considered mesotrophic, which might have occasioned the high density of organisms and the occurrence of the Cladocera male.
\end{abstract}

Key Words: Zooplankton. Priority areas. Biodiversity

\title{
DOS ZOOPLANCTON COMUNIDAD COMPARACIÓN DE CUERPOS DE AGUA EN LA SIERRA DE MANTIQUEIRA - $M G$
}

\begin{abstract}
RESUMEN
La Sierra de Mantiqueira es un área prioritaria de conservación con muchas pequeñas zonas de agua, superficial e invadidas por las malas hierbas. Este estudio tuvo como objetivo llevar a cabo una encuesta a la comunidad de zooplancton en dos zonas de pequeña extensión y profundidad del agua en lugares de la región de la Serra da Mantiqueira Camanducaia / Monte Verde-MG. Muestras cualitativas fueron tomadas (red de $68 \mathrm{mM}$ ) y cuantitativa (100L) desde el borde de la zona de agua, en febrero y junio de 2010. Los parámetros físicos y químicos $(\mathrm{pH}$, conductividad eléctrica, temperatura y oxígeno disuelto) del agua se midieron con multisensor Horiba T-22 y se recogieron muestras de agua para determinar la clorofila, los nutrientes y la materia en suspensión. Los resultados de las variables físicas y químicas mostraron una variación estacional con aumento de la temperatura del agua y la conductividad eléctrica. La comunidad de zooplancton estuvo representada por 26 especies distribuidas entre Cladocera, copépodos y rotíferos, con la riqueza de especies de rotíferos debido a su amplia distribución, seguido por Cladocera, donde la familia Chydoridae (6) fue la más representativa debido a la presencia de malas hierbas en esas zonas de agua. Ambas zonas de agua están en proceso de eutrofización la primera colección se caracterizo como oligotrófico y la secunda de la presa Pinga da Banana como mesotrófico lo que pudo haber causado las altas densidades de organismos y la ocurrencia de Cladocera macho.
\end{abstract}

PALABRAS CLAVE: Zooplâncton. Áreas prioritárias. Biodiversidad 


\section{INTRODUÇÃO}

O Brasil possui um grande potencial hídrico, por suas características topográficas, climáticas e extensa rede de drenagem. O represamento de rios, para a construção de pequenas represas e lagos artificiais (açudes) são comuns em propriedades rurais e urbanas brasileiras. Estes ambientes são muito importantes, tanto no ponto de vista ecológico quanto o social, a heterogeneidade de habitats encontrada nestes ambientes possibilita uma grande diversidade de espécies, além de serem utilizados para o armazenamento de água, abastecimento, irrigação e piscicultura (DANTAS et al, 2009; SERAFIM-JUNIOR, et al 2010; AMORIM, 2014).

Açudes pequenos e rasos tem grande influência do entorno, das flutuações do nível da água, da concentração de detritos e da grande quantidade de macrófitas, o que possibilita a existência de muitos micro-habitats (POMPÊO et al, 1997; SCHEFFER; NES, 2007). O maior contato com o ambiente terrestre, o pequeno volume de água e baixo aporte de água resulta em maior conexão bentônicopelágico e maior impacto do sedimento no conteúdo de nutrientes da água (TESSIER; WOODRUFF, 2002), o que deixa o ambiente favorável para várias espécies de macrófitas e invertebrados (PALIK et al, 2001, MAIA-BARBOSA et al, 2014).

Consequentemente as características dos pequenos corpos d'água são favoráveis à comunidade zooplanctônica (ELMOOR-LOUREIRO, 2007) que é composta por um conjunto de organismos microscópicos que habitam diversos tipos de ecossistemas aquáticos. Entre os grupos que constituem esta comunidade estão os rotíferos, copépodes, cladóceros, protozoários e larvas de insetos (WETZEL, 1993).

A estrutura da comunidade zooplanctônica depende de inúmeros fatores e processos evolutivos, como a presença de predadores e outras características físicas, químicas e biológicas. De acordo com as características e condições do meio as alterações na comunidade zooplanctônica podem ser tanto quantitativas (densidade e abundância de indivíduos) como qualitativas (composição e riqueza de espécies) em detrimento das mudanças abióticas (COELHO-BOTELHO, 2004; SILVA, 2015). A poluição, a eutrofização, o assoreamento, a construção de barragens e a introdução de espécies têm sido algumas das principais causas da 
diminuição da biodiversidade em ecossistemas aquáticos continentais brasileiros (AGOSTINHO; HAHN, 2005).

Estudos ecológicos do zooplâncton são importantes, pois estes organismos são importantes na manutenção do equilíbrio do ambiente aquático, podendo controlar a densidade da comunidade fitoplanctônica, servir de alimento para os peixes (ARAGÃO et al, 2004), assim transferir energia na cadeia trófica (ALMEIDA et al., 2010) e são considerados bons indicadores biológicos da qualidade da água (LANSAC-TÔHA et al, 2004; MATSUMURA-TUNDISI; TUNDISI, 2005).

A Serra da Mantiqueira é uma região rica em pequenos açudes, córregos e riachos, que têm suas nascentes na Serra com água de boa qualidade, frias, bem oxigenada, ambientes com características favoráveis a uma grande biodiversidade zooplanctônica. É uma região ampla que se estende pelo leste do Estado de São Paulo, sul de Minas Gerais e sudoeste do Rio de Janeiro (BRAGA, 2004). É considerada pela Fundação Biodiversitas como uma área prioritária de conservação, as florestas de altitude destacam-se por notáveis endemismos propiciados pelo isolamento geográfico de conjuntos serranos (DRUMMOND et al, 2005). Estes corpos d'água estão localizados em altitude elevadas, e por isso estão expostos a grandes alterações físicas e químicas (BENITES et al, 2003), como as diferenças de temperatura ao longo do ano, o que pode resultar em mudanças na comunidade zooplanctônica.

Considerando a contribuição dos corpos d'água menores para a diversidade de espécies, o presente estudo visou realizar um levantamento da comunidade zooplanctônica em dois corpos d' água pequenos e rasos, localizados em propriedades privadas na região da Serra da Mantiqueira-MG, para contribuir com novas informações sobre a biodiversidade do zooplâncton na região.

\section{1 ÁREA DE ESTUDO}

O estudo foi realizado em dois corpos d'água (açudes) de pequena extensão e profundidade, dentro de propriedades rurais da região da Serra da Mantiqueira, portanto com influência antrópica. São ambientes localizados em grandes altitudes 1042m (Açude João Costura) e 1004m (Açude Pinga da Banana), ou seja, expostos a diversas variações químicas e físicas do ambiente. 
Estes ambientes são utilizados para dessedentação animal, pesca e abastecimento de água em residências e na agricultura. $\mathrm{O}$ açude João Costura tem grande quantidade de macrófitas e plantações de batata, produção de mudas de eucalipto e várias casas no entorno, o que contribui para a degradação da qualidade da água. $\mathrm{O}$ açude Pinga da Banana tem muitas macrófitas, um fragmento de mata ao fundo e gado no entorno (Figura 1).

Figura 1 Mapa com a localização dos corpos d'água da região da Serra da Mantiqueira- MG.

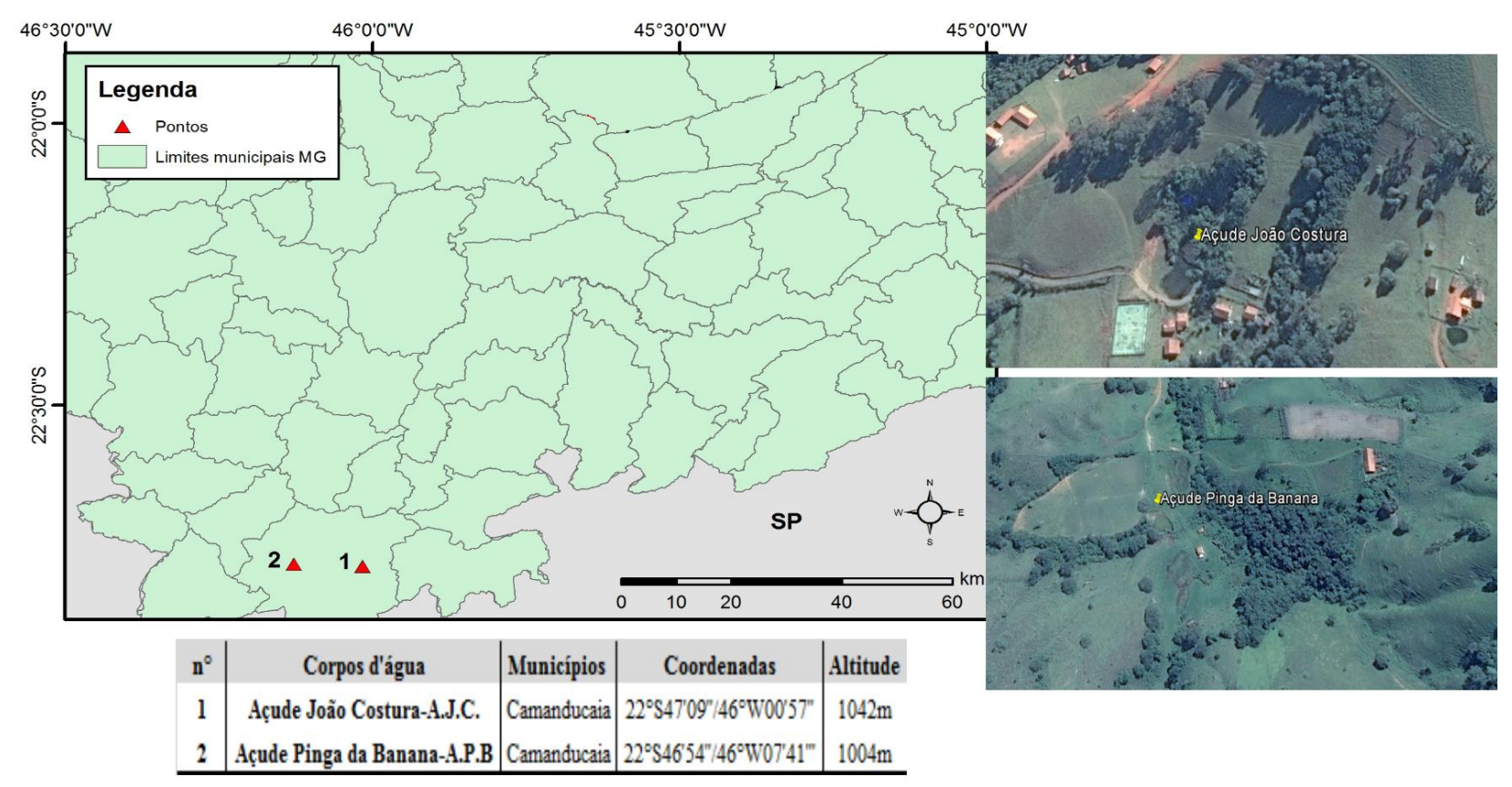

Fonte: ArcGIS versão 9.3, 2011

\section{OBJETIVOS}

O objetivo do presente trabalho foi conhecer a composição e abundância da comunidade zooplanctônica de dois corpos d'água da região de Monte Verde (Camanducaia-MG) na Serra da Mantiqueira relacionando-as com as condições físicas e químicas da água. 


\section{METODOLOGIA}

As coletas foram realizadas em 3/03/2010 (período chuvoso) e 30/06/2010 (período seco), e os pontos georreferenciados por um GPS Garmin.

A medida da temperatura da água, da concentração de oxigênio dissolvido, da condutividade elétrica e do $\mathrm{pH}$ foi realizada na superfície da água com um multisensor Horiba U-22. A concentração do material em suspensão foi determinada pelo método gravimétrico descrito por Teixeira et al., (1965). As determinações da concentração de clorofila a foram realizadas pelo método de extração com acetona 90\% (GOLTERMAN et al., 1978). As coletas de zooplâncton para a análise qualitativa foram realizadas por meio de arrastos horizontais na coluna d'água com uma rede de plâncton com abertura de malha $68 \mu \mathrm{m}$. Para amostras quantitativas, devido à pequena profundidade do corpo d'água ( $<2,5$ metros), foram coletados 100 litros de água, com um balde de 10 litros e filtrados em rede de plâncton. O material coletado foi preservado com formol em concentração final de $4 \%$, saturado com açúcar. As contagens e identificações de Cladocera, Copepoda e Rotifera foram realizadas em microscópio estereoscópio (aumento até 50x) e microscópio óptico (aumento até 1000x), com bibliografia especializada (SMIRNOV, 1974; KOSTE, 1978; NOGRADY et al, 1993; SEGERS, 1995; ELMOOR-LOUREIRO, 1997). As amostras do zooplâncton foram depositadas na coleção de amostras do Laboratório de Limnologia da UNIFAL-MG, Brasil.

\section{RESULTADOS E DISCUSSÃO}

Os corpos d'água são pequenos, rasos (de 0,5 a $2,5 \mathrm{~m}$ de profundidade) e colonizados por macrófitas. A água relativamente estagnada favorece certas espécies da flora e fauna e muitas vezes torna o ambiente relativamente mais heterogêneo, resultando desta forma numa maior diversidade biológica global por unidade de área (OERTLI et al, 2000; OERTLI et al, 2002).

Os maiores valores de temperatura foram registrados em fevereiro de 2010, período referente ao verão com maior incidência solar. A temperatura da água pode influenciar o metabolismo, desenvolvimento e crescimento de vários organismos aquáticos, podendo influenciar a diversidade e densidade das espécies 
zooplanctônicas (MORAES, 2001). A condutividade no presente estudo foi baixa (de 30 a $48 \mu$ S.cm-1) em relação ao estudo SANTOS-WISNIEWSKI et al,(2002) também em ambientes rasos da Serra da Mantiqueira (12 a $150 \mu$ S.cm-1). As características do solo e o uso da região podem influenciar na condutividade, a decomposição da matéria orgânica pode provocar um aumento nos valores de condutividade elétrica à medida que este processo é intensificado (MINILLO, 2005), os ambientes em estudo tem menor ação antrópica o que provavelmente levou terem menor condutividade.

$\mathrm{O} \mathrm{pH}$ da água destes ambientes foi ácido nas duas amostragens, variando de 4,3 a 5,15. O caráter ácido das águas provém dos solos turfosos resultantes da vegetação alpina e matas de altitude encontradas na Serra da Mantiqueira (FRANÇA, STEHMANN, 2004). As águas são bem oxigenadas (5,3 a 7,75 mg. $\left.\mathrm{L}^{-1}\right)$, pois a pequena profundidade e a ação dos ventos favorece a homogeneização da coluna d'água, aumentando a concentração do oxigênio dissolvido (NEGREIROS, 2010). Santos-Wisniewski et al (2002) em um trabalho sobre Cladocera nos corpos d'água da Serra da Mantiqueira, também encontrou ambientes com pH entre 4,3 e 6,7 e águas bem oxigenadas sendo os valores próximos ao encontrado no presente estudo. (Tabela 1).

Tabela 1. Variáveis físicas e químicas de fevereiro e junho de 2010, dos açudes João Costura e Pinga da Banana amostrados na Serra da Mantiqueira.

\begin{tabular}{c|c|c|c|c}
\cline { 2 - 5 } & \multicolumn{2}{c|}{ Fevereiro } & \multicolumn{2}{c}{ Junho } \\
\cline { 2 - 5 } pH & 4,3 & 5,1 & 4,8 & $\mathbf{5 , 1 5}$ \\
\hline $\begin{array}{c}\text { Condutividade } \\
\mu \text { s.cm }^{-1}\end{array}$ & 32 & 48 & 30 & 46,5 \\
\hline $\begin{array}{c}\text { Temperatura da } \\
\text { Água }{ }^{\circ} \mathrm{C}\end{array}$ & 33,1 & 28,5 & 21 & 24,17 \\
\hline $\begin{array}{c}\text { Oxigênio } \\
\text { Dissolvido } \text { mg. }^{-1}\end{array}$ & 5,3 & 6,1 & 6,3 & 7,75 \\
\hline
\end{tabular}

Fonte: Do autor, 2015

As variáveis ambientais associadas à presença de macrófitas em pequenos corpos d'água é um forte preditor de condições favoráveis para manter a grande biodiversidade planctônica e da macrofauna associada a plantas (ZENG et al, 2012; 
SIPAÚBA-TAVARES; DIAS, 2014). Esta heterogeneidade ambiental gerada por estas características contribuiu com a riqueza de espécies destes ambientes, onde foram identificados 26 táxons da comunidade zooplanctônica, 13 de Rotifera, 10 de Cladocera e de 3 Copepoda (Tabela 2).

No presente estudo a riqueza de espécies por corpo d'água foi de 15 no açude João Costura e 19 no açude Pinga da Banana. Rocha et al. (1995), em um levantamento sobre o número de espécies dos grupos zooplanctônicos em 22 corpos d'água brasileiros, encontraram uma variação de 11 a 196 espécies por corpo de água. Para 23 reservatórios do estado de São Paulo, Matsumura-Tundisi, (1999) encontraram riquezas de espécies variando de 7,7 a 98 espécies por corpo d'água. Nestes ambientes a grande maioria das espécies era típica de região limnética, enquanto que no presente estudo foi observada uma grande contribuição de organismos da região litorânea no açude João Costura e de organismos de região limnética no açude Pinga da Banana.

Os cladóceros tiveram grande representatividade na riqueza de espécies sendo a maior (6) no açude João Costura na primeira coleta de 2010. As famílias Ilyocryptidae e Chydoridae foram as mais representativas, com maior riqueza: Alona guttata, Alona yara, Chydorus eurynotus, Chydorus pubescens, Coronatella monacantha, Ilyocryptus spinifer e Leydigia sp. A grande quantidade de macrófitas nestes ambientes provavelmente possibilitou o predomínio desta família que normalmente vive no fundo ou associada com a vegetação (Fryer, 1995, NESSIMIAN; De-LIMA, 1997, SANTOS-WISNIEWSKI et al, 2002). (Figura 2)

Entre os grupos da comunidade zooplanctônica, os rotíferos foram os mais abundantes em fevereiro de 2010 nos dois ambientes amostrados. Rotíferos normalmente predominam em ambientes aquáticos, tanto em riqueza quanto em densidade, por colonizarem diversos ambientes, apresentarem altas taxas reprodutivas e curto ciclo de vida (DAHMS et al., 2011). 
Tabela 2. Ocorrência das espécies zooplanctônicas e valores do Índice de Constância de Dajoz (ICD) dos corpos d'água amostrados na região da Serra da Mantiqueira nos meses de fevereiro e de junho de 2010.

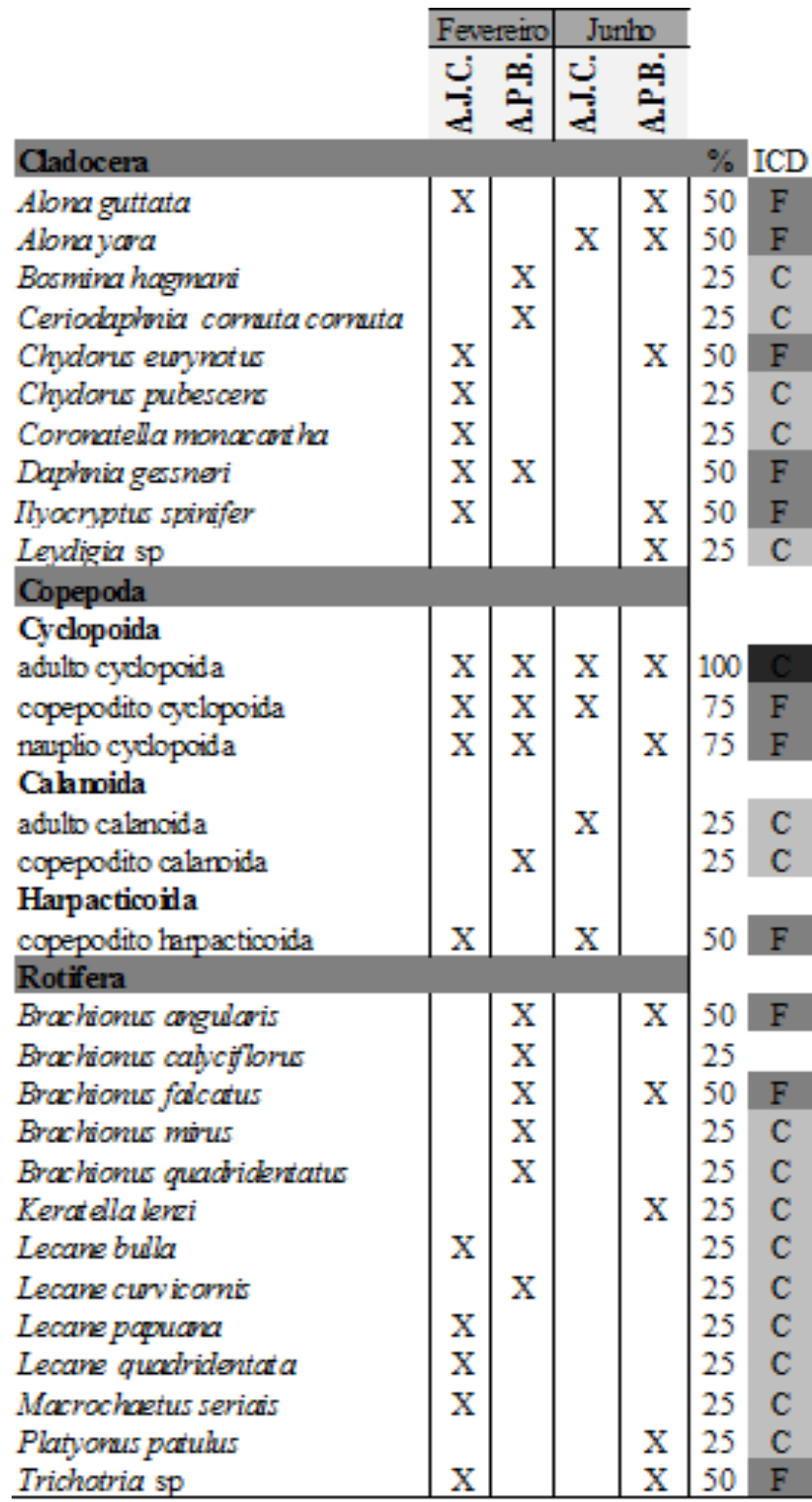

Fonte: Do autor, 2015 
Figura 2 Riqueza de espécies da comunidade zooplanctônica nos corpos d'água da região da Serra da Mantiqueira em fevereiro e junho em 2010.

- Cladocera $\quad$ Copepoda $\quad$ Rotifera

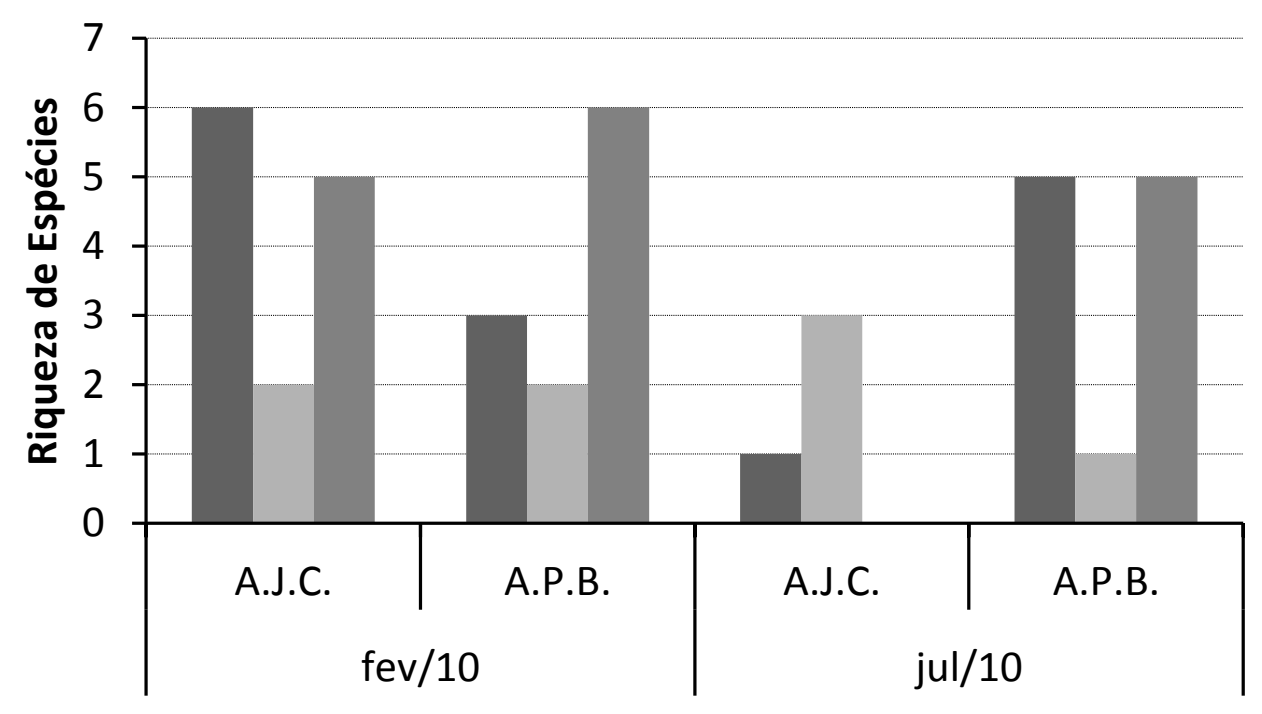

Fonte: Do autor, 2015

As maiores densidades de organismos zooplanctônicos ocorreram no açude Pinga da Banana nas duas coletas fevereiro e julho de 2010, com a densidade de fevereiro muito superior as demais amostragens. $O$ açude Pinga da Banana é um ambiente com grande entrada de nutrientes do entorno e com presença de macrófitas o que pode ter influenciado as grandes densidades de organismos (HART; BYCHEK, 2011). Os rotíferos foram predominantes entre os grupos zooplanctônicos no mês de fevereiro nos dois ambientes, já em julho os copépodos foram predominantes (Figura 3).

No grupo Copepoda foram registradas as três ordens: Calanoida, Cyclopoida e Harpacticoida, com maiores densidades de organismos da ordem Cyclopoida nos dois corpos d'água. Estes açudes estão expostos a forte ação antrópica o que provavelmente possibilitou um ambiente propicio para a ordem, que assim como os Rotiferos aparecem em maior densidade em ambientes eutrofizados (HART; BYCHEK, 2011). 
Figura 3 Densidade de organismos zooplanctônicos $\left(\right.$ Ind. $\mathrm{m}^{-3}$ ) nos corpos d'água da região da Serra da Mantiqueira em fevereiro e junho em 2010.

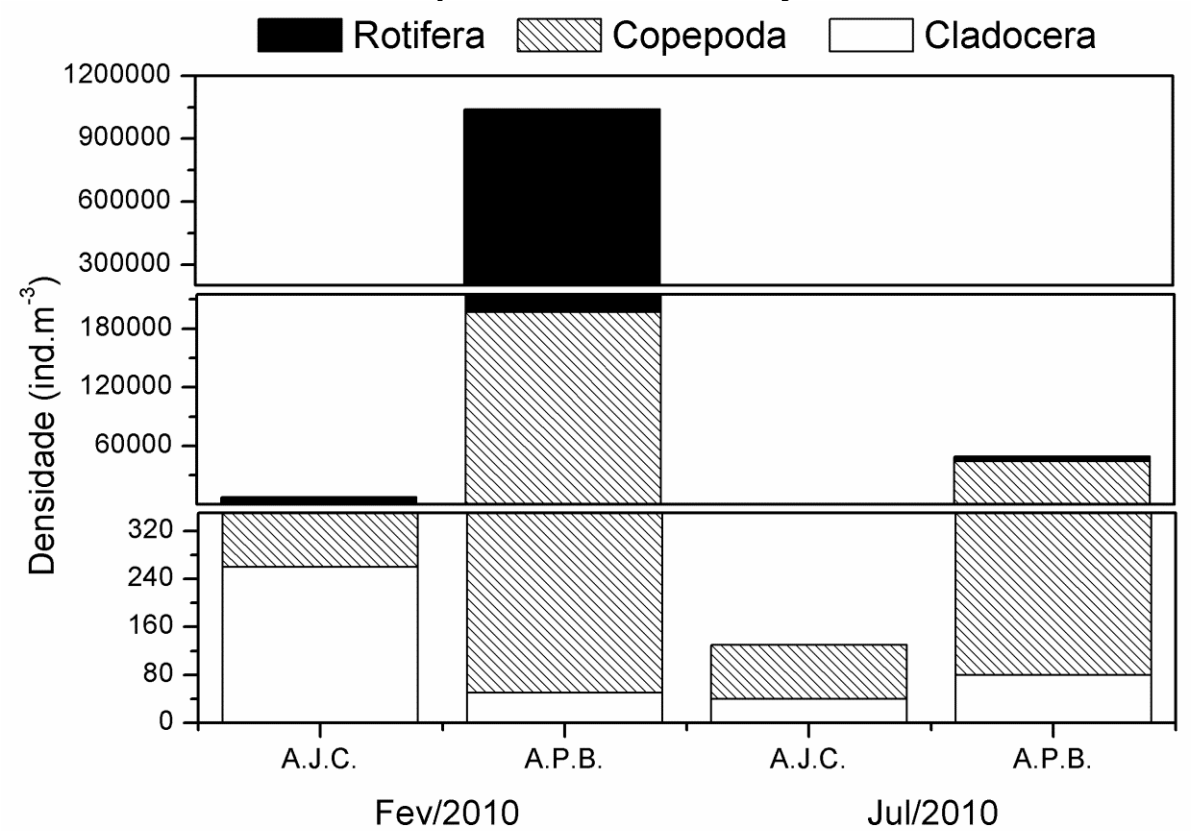

Fonte: Do autor, 2015

Entre os dois ambientes em estudo o açude João Costura foi o que teve maior riqueza (13), próximo do número registrado no açude Pinga da Banana (11). São ambientes com características semelhantes pequenos, rasos, colonizados por macrófitas e ação antrópica no entorno. A riqueza de espécies do açude João Costura diminuiu de uma coleta para outra indo de 13 para 4, a menor riqueza foi registrada no período referente ao inverno, em que a temperatura é mais baixa o que pode influenciar o metabolismo, desenvolvimento e crescimento de vários organismos zooplanctônicos (MORAES, 2001).

Já o açude Pinga da Banana manteve a mesma riqueza (11) e maiores valores de densidade durante os dois períodos de coleta. Neste açude foi registrado um macho de Leydigia sp na segunda coleta. Vários fatores podem levar os cladóceros a se reproduzirem sexuadamente como a temperatura, superpopulação e a eutrofização (SANTANGELO, 2009). Características observadas no corpo d'água durante a segunda coleta, como diminuição da temperatura, grandes densidades de Cyclopoida e de algumas espécies como Brachionus falcatus e Keratella lenzi, além do aumento índice do estado trófico (Figura 4), podem ter levado a ocorrência de macho. 
Figura 4 Índice de Estado Trófico (IET) dos cinco corpos d'água amostrados na região da Serra da Mantiqueira nos meses de fevereiro (estação chuvosa) e de junho (estação seca). Oligotrófico - IET < 44; mesotrófico - $44<$ IET < 54 e eutrófico - IET > 54.

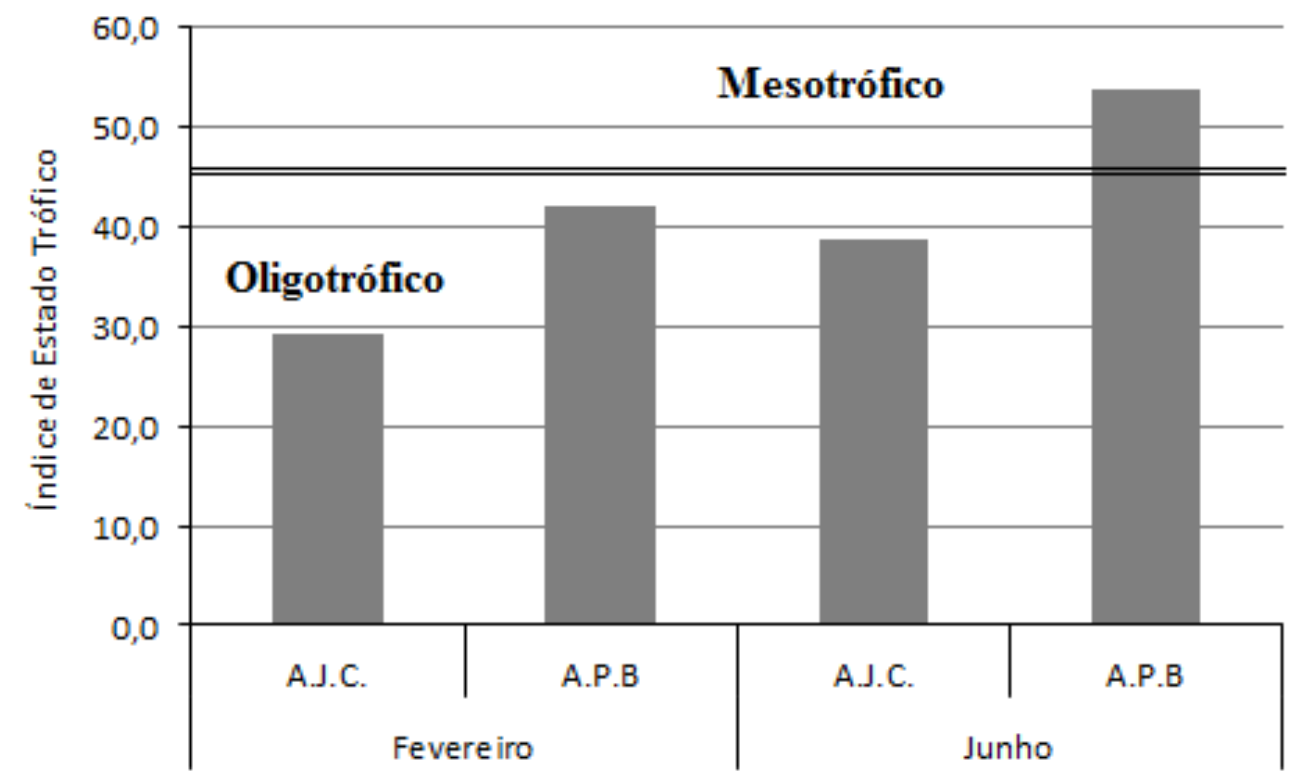

Fonte: Do autor, 2015

O maior grau de trofia (mesotrófico) no açude Pinga da Banana pode ter estimulado o desenvolvimento da biomassa das algas e consequentemente aumentado a disponibilidade de alimento, o que contribuiu para o aumento da riqueza de espécies e densidade de organismos neste ambiente.

\section{CONCLUSÃO}

Os ambientes são pequenos, rasos e colonizados por macrófitas, o que proporciona grande heterogeneidade de habitats. São ambientes propícios para os organismos de região litorânea da comunidade zooplanctônica como Chydoridae e llyocryptidae. O maior grau de trofia no açude Pinga da Banana favoreceu as grandes densidades de Rotifera, Copepoda e a ocorrência do macho de Leydigia sp. As características observadas nestes ambientes demonstram a importância de preservá-los e intensificar os estudos limnicos na região da Serra da Mantiqueira. 


\section{REFERÊNCIAS}

AGOSTINHO, A. A.; HAHN, N. S. A planície de inundação do Alto Rio Paraná: Aspectos físicos, biológicos socioeconômicos. Maringá: EDUEM, 460p. Disponivel em: <http://www.comitesm.sp.gov.br/serramantiqueira.php>. Acesso em: 4 out. 2013. 2005.

ALMEIDA V. L. S. et al. O zooplâncton de água doce e seu estudo em reservatórios do Nordeste do Brasil. In: MOURA, A. N. et al. (eds.). Reservatórios do Nordeste do Brasil: biodiversidade, ecologia e manejo, Bauru: Canal 6. 2010, p. 441-475.

AMORIM, F. Seca ameaça turismo em cidades mineiras. Folha de São Paulo, Ribeirão Preto, 21 mai. 2014. Caderno Cotidiano. Disponível em: < http://www1.folha.uol.com.br/cotidiano/ribeiraopreto/2014/05/1457473-seca-ameaca-turismo-emcidades-mineiras.shtml>. Acesso em: 15 set. 2014.

ARAGÃO, C. et al. Amino acid pools of rotifers and Artemia under different conditions: nutritional implications for fish larvae. Aquaculture, v. 234, 2004, p. 429 - 445.

BRAGA, F. M. S. Habitat, distribuição e aspectos adaptativos de peixes da microbacia do ribeirão Grande, Estado de São Paulo, Brasil. Acta Scientarum, Biological Sciences, v. 26, n. 1, 2004, p. 31-36.

BENITES, V. M.; CAIAFA, A. N.; MENDONÇA, E. S.; SCHAEFER, C. E.; KER, J. C. Solos e Vegetação nos Complexos Rupestres de Altitude da Mantiqueira e do Espinhaço. Floresta e Ambiente, v. 10, n. 1, 2003, p. 76-85.

COELHO-BOTELHO, M. J. Dinâmica da comunidade zooplanctônica e sua relação com o grau de trofia em reservatório. Boletim da CETESB. Disponível em: <http://www.cetesb.sp.gov.br>. Acesso em 16 set. 2014. 2004.

DAHMS, HU., HAGIWARA, A., LEE, JS, Ecotoxicology, ecophysiology, and mechanistic studies with rotifers. Aquatic Toxicology (Amsterdam, Netherlands), vol. 101, n.1. 2011, p.1-12.

DANTAS, Ê. W.; ALMEIDA, V. L. S.; BARBOSA, J. E. L.; BITTENCOURT-OLIVEIRA, M. C.; MOURA, A. N. Efeito das variáveis abióticas e do fitoplâncton sobre a comunidade zooplanctônica em um reservatório do Nordeste brasileiro. Iheringia, Sér. Zool. v. 99, n. 2, 2009, p. 132-141.

DUKA, S.; CULLAJ, A. Evaluation of chlorophyll as the primary index for trophic state classification. J. Environ. Prot. Ecol., v. 10, n. 2, p. 401-410, 2009.

DRUMMOND, G. M.; MARTINS, C. S.; MACHADO, A. B. M.; SEBAIO, F. A.; ANTONINI, Y. Biodiversidade em Minas Gerais. 2. ed. Belo Horizonte: Fund. Biodiversitas/MG. 2005, 222 p.

ELMOOR-LOUREIRO, L. M. A. Manual de identificação de Cladóceros límnicos do Brasil. Brasilia: Editora Universa. $1997.156 \mathrm{p}$.

ELMOOR-LOUREIRO, L. M. A. A. Phytophilous cladocerans (Crustacea, Anomopoda and Ctenopoda) from Paranã River Valley, Goias, Brazil. Revista Brasileira de Zoologia, v. 24, n. 2, 2007, p. 344352.

ESRI. ArcGIS Desktop: Release 9.3. Redlands, CA: Environmental Systems Research Institute. Disponivel em <https://www.arcgis.com/home/>. Acesso em 25 de maio de 2015. 2011.

FRANÇA, G. S.; STEHMANN, J. R. Composição florística e estrutura do componente arbóreo de uma floresta altimontana no município de Camanducaia, Minas Gerais, Brasil., Revista Brasileira de Botânica, 2004. v.27, p.19-30. 
FRYER, G. Phylogeny and adaptive radiation within the Anomopoda: a preliminary exploration. Hydrobiologia, 1995 v. 307, p. 57-68.

GOLTERMAN, H.L.; CLYMO. R.S.; OHNSTAD, M.A.M. Methods for physical and chemical analysis of freshwaters. Blackwell Scientific Publications, 1978, 213p.

HART, R.C.; BYCHEK, E.A. Body size in freshwater planktonic crustaceans: an overview of extrinsic determinants and modifying influences of biotic interactions. Hydrobiologia, 2011 v. 668, n. 1, p. 61108.

KOSTE, W.. Rotatoria die radertiere mitteleuropas, Übeiordnung Monogononta. Berlim: Gebriider Bernträger, 1978, $1010 \mathrm{p}$.

LANSAC-TÔHA, F. A.; BONECKER, C. C.; VELHO, L. F. M. Composition, species richness and abundance of zooplankton community. In: SALGADO-MALDONADO, G.; ALDRETE, A. N. G.; VIDALMARTÍNEZ, V. M. Metazoan parasites in the tropics: a systematic and ecological perspective. Universidad Nacional Autonoma (UNAM), Mexico. p. 25-60, 2004.

MAIA-BARBOSA, P. M.; MENENDEZ, R. M; PUJONI, D. G. F.; BRITO, S. L.; AOKI, A.; BARBOSA, F. A. R. Zooplankton (Copepoda, Rotifera, Cladocera and Protozoa: Amoeba Testacea) from natural lakes of the middle Rio Doce basin, Minas Gerais, Brazil. Biota Neotrop., v. 14, n. 1, 2014, p. 1-20.

MATSUMURA-TUNDISI, T.; TUNDISI, J. G. Plankton richness in a eutrophic reservoir (Barra Bonita Reservoir, SP, Brazil). Hydrobiologia, Aquatic Biodiversity II, v. 542, n. 1, 2005, p. 367-378.

MATSUMURA-TUNDISI, T. Diversidade de zooplâncton em represa do Brasil. In: Henry, R. Ecologia de Reservatórios: Estrutura, função e Aspectos Sociais. Cap.2. FUNDIBIO: FAPESP,1999,p.3954 .

MINILLO, A. Análise da distribuição, densidade e toxicidade de florações de cianobactérias em reservatórios do médio e baixo rio Tietê (SP) e relação com as características limnológicas do sistema. 2005, 400f. Tese (Doutorado em Engenharia Ambiental) - Centro de Recursos Hídricos e Ecologia Aplicada. Escola de Engenharia de São Carlos, USP,São Carlos, USP, 2005.

MORAES, A.J. Manual para avaliação da qualidade da água. São Carlos: Rima. 2001. v. 500, 45 p.

NEGREIROS, N. F. Variação anual da diversidade e produção secundária de rotifera do reservatório da UHE DE Furnas-MG, Brasil. 2010 212f. Dissertação (Mestrado em Ecologia e Recursos Naturais) - Universidade Federal de São Carlos - Ufscar. São Carlos. 2010.

NESSIMIAN, J. L. ; De-LIMA, I. H. A. G. Colonização de três espécies de macrófitas por macroinvertebrados aquáticos em um brejo no litoral do estado do Rio de Janeiro. Acta Limnologica Brasiliensia, 1997, v. 9, p. 149-163.

NOGRADY, T.; WALLACE, RL.; SNELL, TW. Rotifera: biology, ecology and systematic. In: DUMONT, HJF. Guides to the identification of the microinvertebrates of the continental waters of the world. Netherlands: SPB Academic Publishing, v.1, 1993, p. 1-142.

OERTLI, B.; AUDERSET-JOYE, D.; CASTELLA, E.; JUGE, R.; CAMBIN, D.; LACHAVANNE, J. B. Diversite Biologique et Typologie ecologique des Etangs et Petits Lacs de Suisse. Geneva: OFEFP, University of Geneva, 2000.

OERTLI, B.; JOYER, D. A.; CATELLA, E.; JUGE, R.; CAMBIN, D.; LACHAVANNE, J. B. Does size matter? The relationship between pond area and biodiversity. Biol. Cons., 2002, v. 104, p. $59-70$.

PALIK, P. B.; BATZER, D. P.; BUECH, R.; NICHOLS, D.; CEASE, K.; EGELAND, L.; STREBLOW, D. $E$. Seasonal pond characteristics across a chronosequence of adjacent forest ages in northern Minnesota, USA. Wetlands, v. 21, n. 4, 2001, p. $532-542$ : 
POMPÊO, M. L. M.; HENRY, R.; MOSCHINI-CARLOS, V.; PADOVANI, C. R. O papel da macrófita aquática Echinochloa polystachya (H.B.K.) Hitchcock na caracterização física e química da água na zona desembocadura do rio Paranapanema na represa de Jurumirim, SP. Brasil. J. Ecol., v. 1, 1997, p. 44-53.

ROCHA, O.; SENDACZ, S.; MATSUMURA-TUNDISI, T. Composition, biomass and productivity of zooplankton in natural lakes and reservoirs in Brazil,. In: TUNDISI, J. G.; BICUDO, C.E.M., MATSUMURA-TUNDISI, T. Limnology in Brazil. ABC/SBL, Rio de Janeiro. 1995. p. 151-166.

SANTANGELO, J. M. Produção, eclosão e implicações ecológicas e evolutivas dos estágios dormentes do zooplâncton. LIMNOtemas, 2009, v.7,p.1-36.

SANTOS-WISNIEWSKI, M. J. et al. Cladocera Chydoridae of high altitude water bodies (Serra da Mantiqueira), in Brazil. Braz. Journ Biology,, 2002. v. 62, n. 4, p. 681-687.

SEGERS, H. Rotifera: the Lecanidae (Monogononta) In: DUMONT, H.J.F. Guides to the identification of the microinvertebrates of the continental waters of the world. Netherlands: SPB Academic, 1995 v.2. 226 p.

SERAFIM-JUNIOR, M.; PERBICHE-NEVES, G. B. L.; GHIDINI, A. R.; CASANOVA, S. M. C. Variação espaço-temporal de Rotifera em um reservatório eutrofizado no sul do Brasil. Iheringia, Sér. Zool., v. 100, n. 3, 2010, p. 233-241.

SILVA, L. C. A comunidade zooplanctônica de rios amazônicos na área de influência da Usina Hidrelétrica de Santo Antônio do Madeira, RO: diferentes abordagens no monitoramento. 2015. 333 Tese (Doutorado em Ecologia e Recursos Naturais) - Universidade Federal de São Carlos, Ufscar, São Carlos, 2015.

SIPAÚBA-TAVARES, L. H.; DIAS, S. G. Water quality and communities associated with macrophytes in a shallow water-supply reservoir on an aquaculture farm. Brazilian Journal of Biology, 2014, v. 74 , n. 2, p. 420-428.

SCHEFFER, M.; NES, E. H. V. Shallow lakes theory revisited: various alternative regimes driven by climate, nutrients, depth and lake size. Hydrobiologia, v. 584, 2007, p. 455-466.

SMIRNOV, N.N. Crustacea: Chydoridae. Jerusalém: Israel Program for Scientific Translation. 1974. $644 \mathrm{p}$.

TEIXEIRA, C.; TUNDISI, J. G. e KUTNER, M. B. Plankton studies in a mangrove. LI: The standingstock and some ecological factors. Bolm. Inst. Oceonogr., v.24, 1965, p.23-41.

TESSIER, A. J.; WOODRUFF, P. Cryptic trophic cascade along a gradient of lake size. Ecology, v. 83, n. 5, 2002, p. 1263-1270.

WETZEL, R.G. Limnology, 2 ed. Philadelphia: Saunders College Publishing, 679p, 1983.

ZENG, J.; BIAN, Y.; XING, P.; WU, Q. L. Macrophyte species drive the variation of bacterioplankton community composition in a shallow freshwater lake. Applied and Environmental Microbiology, 2012, v. 78, n. 1, p. 177-184. 